a

Cell types of the normal olfactory epithelium

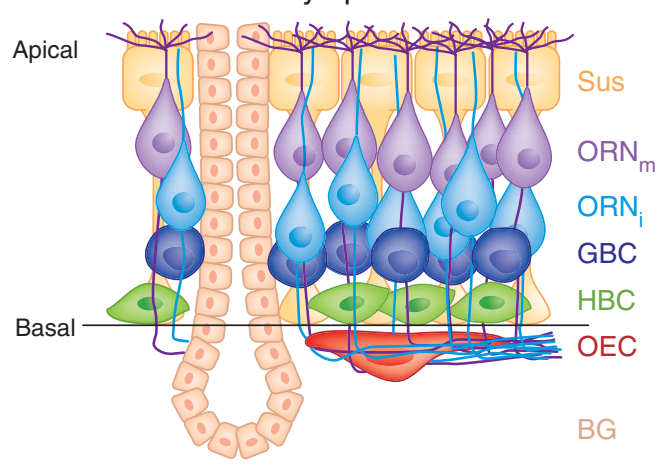

b

Neuronal turnover and neuron-specific injury

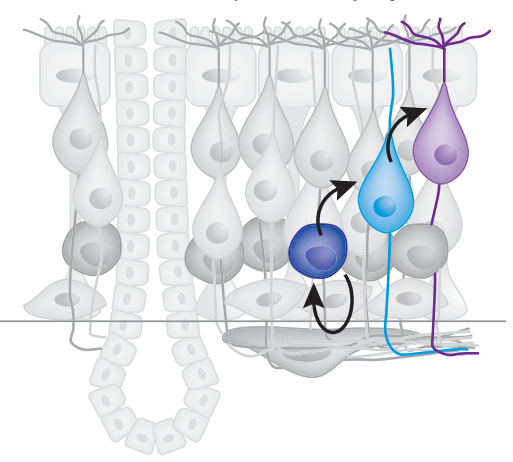

C

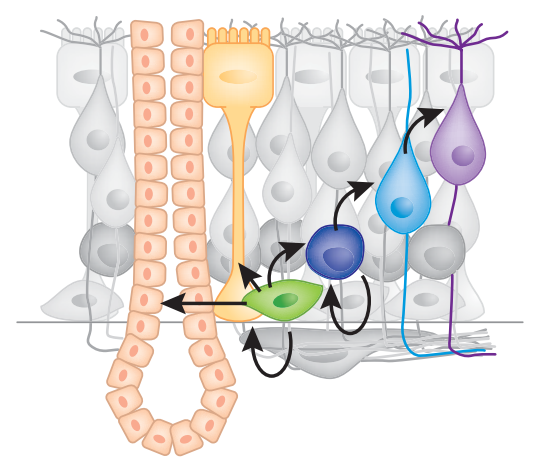

Figure 1 Model of cell lineage relationships in the olfactory epithelium. Stem cells of the olfactory epithelium replace ORNs and non-neuronal support cells throughout life. (a) The pseudostratified olfactory epithelium is populated by sustentacular support cells (Sus), mature and immature ORNs (ORN ${ }_{m}$ and ORN ${ }_{i}$, respectively), OECs, cells of Bowman's gland (BG) and two types of progenitors (GBCs and HBCs). (b) GBCs have the capacity to regenerate the ORN population under normal conditions and after experimental ablation of ORNs. (c) More severe ablation conditions that cause the loss of both neuronal and non-neuronal cells lead to the recruitment of HBCs, which proliferate and differentiate into all of the mature cell types of the olfactory epithelium. It is unclear whether the differentiation of non-neuronal cells from HBCs involves intermediate cell types analogous to the GBCs of the neuronal lineage.

However, the extent to which severe tissue injury represents the normal response of the olfactory epithelium to environmental insults over the course of everyday life (such as the sooty and smoggy air common to urban environments) is unclear. It also remains to be determined what intermediate cell types (if any) exist between the HBCs and nonneuronal support cells. Lineage tracing of the sort described by Leung et al. ${ }^{3}$ targeting the GBCs should clarify the true developmental potential of these proliferating cells in vivo.

The present findings ${ }^{3}$ will surely stimulate future investigations of olfactory stem cell biology. For example, with the latest tools for studying HBCs and their descendants, we are now in a position to elucidate the signaling pathways that influence the proliferation and differentiation of this stem cell population. It will also be interesting to determine the developmental origins of HBCs in the olfactory epithelium. One curiosity is that keratin $\mathrm{K} 5$, along with other molecular markers for HBCs, is only expressed in HBCs from late-stage embryos and postnatal animals ${ }^{2,3}$. Yet the olfactory epithelium undergoes dramatic expansion and growth earlier in embryogenesis. Presumably the cells in the embryonic olfactory epithelium are also derived from a tissue-specific stem cell. Intriguingly, keratin K5-expressing cells are detected in a ventral-to-dorsal progression during development, suggesting either a migration of these cells from a ventral site or a wave of maturation of existing cells ${ }^{2,3}$. Determining whether there are distinct lineages of HBCs in embryonic versus postnatal olfactory epithelium, analogous to the primitive and definitive erythropoietic lineages ${ }^{14}$, will be an important topic for future inquiry. Finally, because the olfactory epithelium is readily accessible to surgical intervention, this structure may prove to be a good source of stem cells for therapeutic applications in regenerative medicine: for example, to generate OECs for promoting axon regeneration after traumatic nerve injury ${ }^{12}$.

\section{COMPETING INTERESTS STATEMENT}

The authors declare no competing financial interests.

1. Graziadei, P.P. \& Graziadei, G.A. J. Neurocytol. 8, 1-18 (1979).

2. Holbrook, E.H., Szumowski, K.E. \& Schwob, J.E. J. Comp. Neurol. 363, 129-146 (1995).

3. Leung, C.T., Coulombe, P.A. \& Reed, R.R Nat. Neurosci. 10, 720-726 (2007).

4. Cau, E., Gradwohl, G., Fode, C. \& Guillemot, F. Development 124, 1611-1621 (1997).

5. Caggiano, M., Kauer, J.S. \& Hunter, D.D. Neuron 13 339-352 (1994).

6. Chen, X., Fang, H. \& Schwob, J.E. J. Comp. Neurol. 469 457-474 (2004).

7. Mackay-Sim, A. \& Kittel, P. J. Neurosci. 11, 979-984 (1991).

8. Huard, J.M. \& Schwob, J.E. Dev. Dyn. 203, 17-26 (1995).

9. Weissman, I.L. Cell 100, 157-168 (2000).

10. Carter, L.A., MacDonald, J.L. \& Roskams, A.J. J. Neurosci. 24, 5670-5683 (2004).

11. Sicard, G. Feron, F., Andrieu, J.L., Holley, A. \& Mackay-Sim, A. Ann. NY Acad. Sci. 855, 223-225 (1998).

12. Raisman, G. \& Li, Y. Nat. Rev. Neurosci. 8, 312-319 (2007).

13. Fuchs, E. Nature $445,834-842$ (2007).

14. Baron, M.H. \& Fraser, S.T. Curr. Opin. Hematol. 12, 217-221 (2005)

\title{
Studying cortical depression in vivo
}

Cortical spreading depression (CSD) is a self-propagating wave of cellular depolarization and cessation of synaptic activity that spreads across the cortex. On page 754, Takano and colleagues use two-photon microscopy to image $\mathrm{NAD}^{+}$and its reduced form $\mathrm{NADH}$, and use oxygen sensor microelectrodes to study the mechanisms behind CSD in live mice. They conclude that the energy consumed to reestablish the ionic gradients that are lost during CSD causes an increase in oxygen demand that exceeds vascular oxygen supply, resulting in severe tissue hypoxia and neuronal swelling. Increasing oxygen availability shortens the duration of CSD. These observations may also be clinically relevant, as CSD is thought to be the neurobiological substrate of migraines with aura, and because CSD may also contribute to injury during stroke. It may also help to explain why migraine sufferers have a higher risk of stroke.

\section{Kalyani Narasimhan}

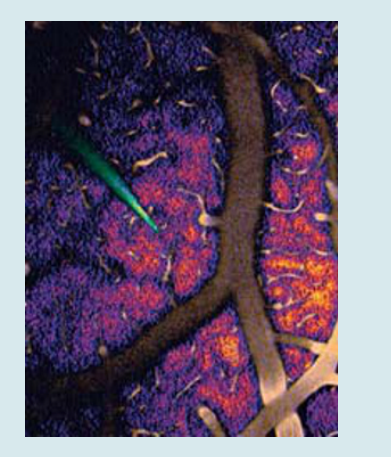

